\title{
Response to children's physical and mental needs during the COVID-19 outbreak
}

\author{
Xiao-Bo Zhang ${ }^{1} \cdot$ Yong-Hao Gui ${ }^{2} \cdot$ Xiu Xu $^{3} \cdot$ Da-Qian Zhu ${ }^{4} \cdot$ Yi-Hui Zhai ${ }^{5,6} \cdot$ Xiao-Ling Ge $^{6} \cdot$ Hong Xu $^{5}$
}

Received: 7 April 2020 / Accepted: 16 April 2020 / Published online: 25 May 2020

(c) Children's Hospital, Zhejiang University School of Medicine 2020

School closure and stay-at-home, as a part of non-pharmaceutical interventions (NPI), have been implemented in China since February as an effective way to mitigate the spread of the virus during the COVID-19 outbreak. As concerns rose over the potential impacts of such NPI measures on children's health, such as longer exposure to digital screens, irregular sleep pattern, weight gain, and loss of cardiorespiratory fitness [1], the Chinese Government, experts on public health, educators on school health, and teachers have been making joint and massive efforts to provide distance learning with well-organized online courses to help.

Children's Hospital of Fudan University is the designated hospital for treating pediatric cases with COVID-19 in Shanghai. As child healthcare providers at the hospital, such concerns caught our attention and we also paid close attention to potential psychological impacts on children, especially those who have suffered from the infection or from other underlying conditions [2]. Thus far, there are no specific medications for COVID-19. The ways that have been proven to be most effective at curbing the virus spread are traditional approaches, such as case isolation, social distancing, and school closure [3]. As child healthcare providers, what can we do when unintended, negative impacts of

Hong Xu

hxu@shmu.edu.cn

1 Department of Respiratory Medicine, Children's Hospital of Fudan University, Shanghai 201102, China

2 Shanghai Medical College, Fudan University, Shanghai 201102, China

3 Department of Child Health Care, Children's Hospital of Fudan University, Shanghai 201102, China

4 Department of Psychology, Children's Hospital of Fudan University, Shanghai 201102, China

5 Department of Nephrology, Children's Hospital of Fudan University, Shanghai 201102, China

6 Department of Statistics and Data Management, Children's Hospital of Fudan University, Shanghai 201102, China these approaches are sustained by children? How can we use today's new concepts and advanced technologies to protect children and to put into practice that children are prioritized in the society, while ensuring the principles of gender equity and geographic distribution? How can we cooperate with experts on public health and with educators on school health to perform health communication and to minimize the impact of the pandemic on children's physical and mental health?

\section{An integrated online solution}

In the context of such a crisis, as the National Children's Medical Center, we launched a special project, the Child Health Initiative for Children and Adolescents (CHI) (https ://erke-he.51 tingyi.com/home/index), to provide multidisciplinary support and services on physical and mental health, to perform health communication, and to relieve anxiety and stress. It is an internet-based interactive platform for children and adolescents that is intended to improve their overall well-being during the COVID-19 pandemic. The platform includes different dimensions, such as disease prevention and treatment, child health communication and science popularization, improvement of children's mental health, and increment of family and community cohesion. Experts which are served on this platform include pediatricians, nurses, pharmacists, social workers, musicians, artists, and educators on school health, as a joint team to provide health service.

The free online medical consultant is a popular part of the project that has been started since February 8. More than 200 doctors specialized in child health care from diversified specialties, including pediatric psychiatry, have been serving online in turn for 12 hours on a daily basis, from 8 am to $8 \mathrm{pm}$. Questions from 32 provinces, municipalities, and autonomous regions in China have been submitted to the platform within the first month of operation. Answers 
were always given promptly online-within 8 minutes in the first week of service. By collecting queries from children and their families, professionals also could spot their needs and thus adjust emergency policies of the hospital and the society as a whole in response. The free online live webcast is another program sought after by users in the project. Experts elaborated on selected topics around children's wellbeing during the live webcast. Utilizing advanced internet and cloud technology, the platform can support multiple live webcasts simultaneously. One live webcast on March 18 hosted by 60 experts from 10 various specialized fields attracted nearly 20,000 online visits within 2 hours. Realtime medical consulting by texting were provided during the 2-hour live webcast to answer questions from the viewers, and frequently asked questions were answered orally and directly.

In addition, the platform is keeping updated the latest COVID-19 pandemic information for helping to relieve anxiety and stress in children and parents. It also informs users of child health management, healthy physical growth, and mental health improvement in various forms, such as text, pictures, videos, audiobooks, and webinars. What's more, it takes advantage of music for soothing emotions, art classes to reduce children's feeling of boredom when being kept to stay home, and tailor-made videos to guide physical activities at home. For those who suffer from anxiety and stress, professional assessment tools are also available on the platform.

\section{Paving way for future approaches}

The CHI project is currently operating smoothly and has received positive user feedbacks. Preliminary online surveys from children and parents have shown that the platform meets their requirements and medical support is the top priority of the service. To make the project live up to its full potential, we plan to expand the assessment of users' needs, to perform thorough user analysis, to prepare better online educational materials and to further evaluate effects, making sure that all such steps abide by the standard health communication process and thus enlarge the positive impact of the project. We are exploring a system and structure that allow medical institutions to join hands with various social sectors by playing up their respective resources and advantages to launch health communication to users. This system may provide insights and experience for the future establishment of health communication channels to the general public under emergent public health conditions.

As the global pandemic of COVID-19 continues, a growing number of countries/territories/areas have enforced school closure, with a serious impact on over 1.3 billion students globally [4]. We believe global cooperation is the real cure to the COVID-19 pandemic. We are keen on looking forward to global collaboration, and we hope the model of active involvement of medical institutions in health communication and promotion can have a long-term effect.

Author contributions ZXB designed the program, revised the paper critically for important intellectual content, and final approval of the version to be published; GYH: designed the program, revised the paper critically for important intellectual content, and final approval of the version to be published; XX designed the program, revised the paper critically for important intellectual content, and final approval of the version to be published; ZDQ designed the program, revised the paper critically for important intellectual content, and final approval of the version to be published; ZYH designed the program, revised the paper critically for important intellectual content, and final approval of the version to be published; GXL designed the program, revised the paper critically for important intellectual content, and final approval of the version to be published; $\mathrm{XH}$ designed the program, revised the paper critically for important intellectual content, and final approval of the version to be published.

Funding Children's Hospital of Fudan University, Emergency Research Program on COVID-19, EKXGZX004.

\section{Compliance with ethical standards}

Ethical approval The study was approved by the Ethical Committee of Children's Hospital of Fudan University (2020-174).

Conflict of interest The authors declare that they have no competing interests.

\section{References}

1. Brazendale K, Beets MW, Weaver RG, Pate RR, TurnerMcGrievy GM, Kaczynski AT, et al. Understanding differences between summer vs. school obesogenic behaviors of children: the structured days hypothesis. Int J Behav Nutr Phys Act. 2017;14:100-13.

2. Brooks SK, Webster RK, Smith LE, Woodland L, Wessely S, Greenberg N, et al. The psychological impact of quarantine and how to reduce it: rapid review of the evidence. Lancet. 2020;395:912-20.

3. Ferguson NM, Laydon D, Nedjati-Gilani G, Imai N, Ainslie K, Baguelin $\mathrm{M}$, et al. Impact of non-pharmaceutical interventions (NPIs) to reduce COVID-19 mortality and healthcare demand. Imperial College COVID-19 Response Team, 16 March 2020. https://doi.org/10.25561/77482. Accessed 23 Mar 2020.

4. 1.37 billion students now home as COVID-19 school closures expand, ministers scale up multimedia approaches to ensure learning continuity. United Nations Educational, Scientific and Cultural Organization. https://en.unesco.org/news/137-billion-stude nts-now-home-covid-19-school-closures-expand-ministers-scale -multimedia. Accessed 2 Apr 2020.

Publisher's Note Springer Nature remains neutral with regard to jurisdictional claims in published maps and institutional affiliations. 